\title{
Professionalism in Language Teaching?*
}

\author{
JANE E. HARDY \\ Wabash College \\ Crawfordsville, Indiana, USA
}

\begin{abstract}
Language teaching is a profession that requires specialized skills. Teachers need a high level of proficiency in the language that they teach in addition to knowledge of second language acquisition and language teaching methodology. However, language teaching is frequently undervalued and misunderstood. This paper examines the (lack of) professionalism in language teaching from two different perspectives. First, the author considers the status of English language teaching around the world, which is adversely affected by the frequent practice of hiring unqualified native speakers. The second section of the paper addresses the current status of foreign language teaching in the United States. In spite of a critical need for foreign language skills in the U.S., language programs are being eliminated at universities around the country, and in some cases classroom instruction is being replaced with self-study software programs.
\end{abstract}

Key words: enseñanza de lenguas, profesionalismo, hablantes nativos, hablantes no nativos

\section{Resumen}

La enseñanza de lenguas es una profesión que requiere destrezas especializadas. Los profesores necesitan un nivel alto de competencia en la lengua que enseñan, y además un conocimiento de la adquisición de segundas lenguas y de metodología. Sin embargo, la enseñanza de lenguas es frecuentemente malentendida y desvalorizada. El presente artículo examina la falta de profesionalismo en la enseñanza de lenguas desde dos perspectivas. Primero, la autora considera perjudicado el estatus de

* An earlier version of this paper was presented at the II Congreso Internacional de la Escuela de Lenguas Modernas: Lenguas, Culturas e Identidades, University of Costa Rica, December 13, 2010. 
la enseñanza del inglés en el mundo debido al empleo de hablantes nativos no calificados. La segunda sección del artículo presenta la situación actual de la enseñanza de lenguas extranjeras en Estados Unidos. A pesar de que existe una necesidad imprescindible para hablantes de otros idiomas, recientemente se están eliminan programas en lenguas modernas en varias universidades en Estados Unidos, y en otros casos los profesores son reemplazados por el estudio individual mediante "software".

Palabras claves: language teaching, professionalism, native speakers, non-native speakers

L anguage teaching is a career that requires specialized skills. First, we need a high level of proficiency in the language we teach, but proficiency alone isn't enough. We also need explicit, declarative knowledge about the language in order to teach it. Finally, we need to know something about the principles of second language acquisition and language teaching methodology. I have long maintained that teaching a language is inherently different from teaching in other disciplines because the content that we teach also serves as the medium of instruction. In spite of the skills needed to teach another language, language teachings tends to be misunderstood and undervalued. In Part 1, I will address the status of English teachers around the world, in particular the issue of native vs. non-native English speaking teachers and the damage done to our field by the hiring of unqualified teachers. In Part 2, I will consider the current state of foreign language teaching and learning within the United States and a disturbing trend to replace teachers with self-study software programs.

\section{Part 1: English Language Teaching around the World}

Peter Medgyes said the following about one subgroup of English language teachers internationally:

...there are thousands of unqualified or underqualified native speakers teaching English in all corners of the world. Most of them are adventurous youngsters with backpacks, who are impelled by a desire to see the world, meet interesting people, learn foreign languages, and meanwhile make a bit of money out of ELT... While sympathising with their stamina and goodwill, I must admit that they are doing considerable disservice to ELT by decreasing the level of professionalism. (Medgyes, 1994: 66)

Megyes is referring to native English speakers who lack formal training in the area of language teaching. There are, of course, plenty of qualified native English-speaking teachers around the world, just as there are non-native 
English-speaking teachers whose level of language proficiency may be inadequate for them to teach the language successfully. However, in the paragraphs that follow, I will focus on the widespread problem of unqualified native English speaking teachers who compete for jobs with fully qualified non-native teachers.

In the United States, English language teaching is not always respected or highly valued. There may be many reasons for this lack of respect, but one reason is surely the common misconception that those who can speak the language are automatically qualified to teach it. ESL is commonly viewed as a job that doesn't require any special training or expertise. Nevertheless, for jobs in the U.S., ESL teachers are commonly required to have a Master's degree in TESOL, language education, or Applied Linguistics; and in fact there are non-native speakers of English who work as English teachers.

However, the situation is often quite different outside of countries where English is spoken as the primary language. This is because of two myths, widely accepted as truths: 1. being a Native Speaker (NS) automatically qualifies a person to teach his or her native language; and 2. a NS of a language is naturally a superior language teacher to a non-native speaker (NNS). To illustrate my point, I will share some anecdotes from personal experience:

Anecdote \#1: I ran into an acquaintance who had heard that I was teaching ESL and he wanted to ask me more about my job. He explained that he had a friend who had taught English in Japan and had reportedly earned quite a lot of money doing it. My acquaintance was interested in making his own fortune teaching English in Japan and wanted to ask me for advice. I recommended that he get a certificate in TESOL before going so that he would know what he was doing. He was clearly not pleased with my advice, and explained that his friend didn't have any credentials in TESOL, but that he had been a successful teacher because he had 'an outgoing personality.'

Anecdote \#2: I had been teaching English in the U.S. for about 8 years when I completed my doctorate. I received a card in the mail from a distant relative by marriage whom I didn't know very well. I was pleased at first that she had taken the time to send me a card congratulating me on completing my degree until I read the last line: "Now you can get a real job." Ironically, the woman who sent me the card was herself a teacher.

Anecdote \#3: I knew an American who was living in Slovenia, where I taught for several years. He was a businessman with no training or experience in language teaching. One day he received a telephone call from a private language school. They had heard that he was a native speaker of English, and offered him a job teaching at their school. (To his credit, he turned down the job.)

Anecdote \#4: I had a colleague in the U.S. who was from Germany. We taught together in the same intensive English program while he was working on his doctoral degree in Language Education. He was a very popular teacher, well-thought of, and nobody questioned his ability to teach in our program even though he was not a native speaker of English. When he completed his degree, he returned to Germany, only to be turned down for several jobs because he was 
not a native speaker of English. His wife, an American, got a job immediately, even though she had fewer formal credentials than he.

Anecdote \#5: I know an American living in Germany who is formally educated, but she moved to Germany with no training or experience in language teaching. Nevertheless, she got a job as an English teacher in Germany (where my former colleague with a $\mathrm{PhD}$ in Language Education was denied a job because he was not a native speaker). I was upset when I heard about her job, and I tried to understand why it bothered me so much. Shouldn't I have been happy for her for getting a job? In trying to understand my reaction, I came up with the following analogy:

What if I moved to Costa Rica with no particular career path, but I wanted a job. I might notice some successful hair salons in San José and decide that I would try to get a job as a hair stylist. After all,

- I have hair.

- I have had hair since I was born. I only had a little as a newborn, but by the time I was a few years old, I had a full head of hair.

- I am educated-I even have a PhD in Linguistics-so I'm sure I'm smart enough to figure out how to do it.

- I have been getting my hair cut for years, and I have observed carefully how it is done.

- I even have experience: I wash and style my own hair; I have used hairdryers, curling irons, and gel; and I have even trimmed my bangs and cut my son's hair.

My analogy may seem humorous, but how is it so different from a NS who arrives in Costa Rica (or any other country) and gets a job teaching English without any training to do so? The untrained NS may claim to be qualified by virtue of knowing the language since early childhood and being educated in some field (although not TESOL); she may also point out that she has gained knowledge of teaching by having studied a foreign language and by observing her foreign language teachers; and she may even have some experience teaching, perhaps teaching as a volunteer or as a private tutor.

However, there are two important differences:

- Most of us would never dream of trying to establish ourselves as hair stylists without formal training, and

- Even if we tried to get a job at a salon, we wouldn't be hired without a license of some sort. Yet a private language school can potentially hire any native English speaker as an English teacher, and no license, diploma, or certificate is required.

Before looking in more detail at native vs. non-native speaking teachers (NESTs vs. non-NESTs) ${ }^{1}$, it is important to define what these terms mean. What is a native speaker? In some cases, the answer is unambiguous. In my own case, 
for example, I was born in the U.S. to monolingual English-speaking parents, and English was the only language I spoke until I took my first foreign language class at the age of 14 . However, there are cases where the definition of the term native speaker is problematic.

In his seminal 1994 book The non-native teacher, Peter Medgyes considers seven possible definitions of native speaker. I will present each below followed by potential complications in their application.

A native speaker of English (as an example) is someone who:

1. was born in an English-speaking country, and/or;

Complications: There are children born in predominantly Spanish-speaking communities in the U.S. (including parts of Florida, Texas, and California) who hear only Spanish spoken at home and in their communities. Would we consider such children native speakers of English just because they were born in the U.S.? Furthermore, what criteria do we use in deciding what constitutes an English-speaking country? People generally cite Great Britain, the United States, Canada, Australia, and New Zealand. But what about Quebec, Canada, where French is the first language? Or the areas of the U.S. in which Spanish predominates? Do we include India, Pakistan, Singapore, Kenya, or Tanzania?

2. acquired English during childhood in an English-speaking family or environment;

Complications: How do we define 'childhood'? Is a child considered a native speaker if he/she learns a language by age 3 ? By age 6 ? By age 10 ? Where is the cut-off? We could revise the definition to a child who learns English during the 'critical period,' but linguists to date have not been able to define set ages when the critical period begins and ends. Do we include people from India or Singapore, for example, who may not speak English at home, but who learn it from a very young age and use it exclusively in school?

3. speaks English as his/her first language;

Complication: A childhood friend of mine who grew up in the United States with a German father and a Brazilian mother. She grew up speaking English, German, and Portuguese, so which is her native language? Or does she have three?

4. has a native-like command of English;

Complications: This is a tautology. We can't use the term 'native' to define the term 'native.' Moreover, how do we measure one's command of English? Are we comparing educated speakers of a language? Do we include uneducated or illiterate native speakers?

5. has the capacity to produce fluent, spontaneous discourse in English;

6 . uses the English language creatively;

Complications: Definitions 5 and 6 are very broad and would include a great many people who do not consider themselves native speakers. There are many educated non-native speakers whose ability to use the English language in a spontaneous, sophisticated, and creative way exceeds that of many native speakers. 
7. has reliable intuitions to distinguish right and wrong forms in English.

Complication: Judgments or intuitions supplied by native speakers (even educated ones) are not always reliable, and often native speakers disagree among themselves. I have also observed highly competent non-native speakers correct non-standard forms used by native speakers.

Building on Medgyes' list of possible definitions, Liu (1999) presents some additional factors to consider in defining nativeness:

1. The order in which languages are learned vs. competence in a language

Consider, for example, someone born in Korea who speaks Korean as a first language, but immigrates to the U.S. at age 6 and eventually becomes more competent in English than in Korean. What's more important: the fact that he learned Korean first, or the fact that he is more competent in English? Is he a NS of English or Korean or both?

2. cultural affiliation or social identity

For example, a Puerto Rican who is bilingual in English and Spanish may prefer to identify herself as a non-native speaker of English, even if her English is flawless, because she identifies herself culturally as Hispanic.

3. ethnicity

English speakers from Hong Kong, Singapore, or India might be less likely regarded or accepted as native speakers because they are not Caucasian and don't fit the stereotype of the Anglo NS. This happens in the U.S. and abroad: students of English as a second language may more readily accept bilingual or non-native Europeans as teachers simply because they look the part.

4. NS and NNS may fall along a continuum rather than being discrete categories

It might make more sense to view individual speaker along a native- -nonnative continuum rather than viewing the distinction as a simple dichotomy. Speakers of multiple languages may also have multiple social identities that they draw from in different professional and social contexts.

Although there is no completely satisfactory definition, people continue to use the terms, and most teachers have a clear self-identity as native or nonnative. Assuming that we can agree on who qualifies as native or non-native, we need to consider how one's nativeness affects his or her ability in the language classroom.

Medgyes (1994) identifies both advantages and disadvantages non-NESTs have in the language classroom. I will present Medgyes' claims below, followed by my own interpretations:

1. In general and on average, non-NESTs are less proficient than NESTs.

Comment: I won't argue this point as long as we are comparing educated NESTs with educated non-NESTs.

2. In general and on average, non-NESTs have less knowledge of English language cultures.

Comment: A NEST would have a superior knowledge of his or her own culture, but there are many different English-speaking cultures that differ considerably from one other. A non-native speaker who has spent time in Australia, 
for instance, would likely have a better knowledge of Australian culture than a North American would.

3. Non-NESTs may experience 'schizophrenia' (role-playing in the classroom)

Comment: By "schizophrenia," Medgyes refers to the fact that non-NESTs belong to one culture, but teach the language of another culture. When a nonNEST enters the classroom, he/she is automatically playing a role. Should he/ she follow rules of conduct of an English-speaking country, or of the native country? For example, does the non-NEST expect students to stand up and greet the teacher? What forms of address are expected? These choices are more natural for the NS who is using the language of his/her own culture.

4. Non-NESTs may suffer an 'inferiority complex'

Comment: Many non-NESTs feel self-conscious about their language knowledge. I have worked as a teacher trainer with many non-NESTs over the years, and they frequently express anxiety over their language ability and fear making mistakes.

On the other hand, Medgyes points out that non-NESTs can:

1. provide a good learner model for imitation;

Comment: A NS is an unrealistic model for most learners. They may realize that they will never speak English as well as a native speaking teacher. However, if their teacher is a non-native, they can see that teacher's language skills as an attainable model.

2. teach language learning strategies more effectively;

Comment: Because they have learned the language themselves, non-NESTs can impart the strategies that they themselves found effective. However, I would argue that a qualified, experienced NEST ought to be able to do this as well.

3. supply learners with more information about the English language;

Comment: From having studied the language explicitly, non-NESTs have a conscious, declarative knowledge of the rules of English grammar. Very often, a NS will be able to tell you what is correct or incorrect, but not be able to explain why. Once again, however, a qualified and experienced NEST should be able to do this as well.

4. anticipate and prevent language difficulties better;

Comment: Non-NESTs can do this because of having learned the language themselves and from knowing their learners' first language (L1). This underscores the importance of NESTs' learning the L1 of their students whenever possible.

5 . be more empathetic to the needs and problems of learners;

Comment: Non-NESTs understand what learners are going through because of having gone through the process themselves. However, this may work in reverse. A non-NEST was in all likelihood a highly successful language learner, perhaps someone to whom the language came easily. This type of teacher may, in fact, be less patient and less empathetic with learners who have trouble with the language. ("I learned English, so why can't they?")

6. make use of the learners' mother tongue;

Comment: Although popular methodology in language teaching discourages the use of L1, it can be a useful tool. NESTs could also potentially do this if they 
take the time and effort to learn their learners' L1 -something which Medgyes and I encourage teachers to do if at all possible.

7. provide a model of international English.

Comment: Increasingly, English acts as a lingua franca between non-native speakers. By some estimates, more than half of the people in the world who speak English are non-native speakers (Willis, 1996; Graddol, 1996; Nunan, 2003), and over half the world's business is conducted in English between people whose first language is not English. In such contexts, a specific national accent could be a disadvantage. Non-natives often find it easier to communicate with other non-natives. Their accents may be more 'neutral' and their language less likely to contain culture-specific references, slang, or idioms which might be inappropriate in an international context. ${ }^{2}$

While we can argue on logical or ideological grounds, there has also been some research comparing the classroom behaviors of NESTs and non-NESTs. Arva \& Medgyes (2000) analyzed lessons taught by 10 secondary school teachers in Hungary, 5 British NS of English and 5 Hungarian teachers, and then interviewed them about their professional behavior, strengths, and weaknesses. The primary advantage attributed to NESTs was their superior competence in English, while lack of knowledge of Hungarian and of the Hungarian examination system was viewed as a handicap. NESTs were also criticized for having a casual attitude and just making friends with the students. One non-NEST complained that the NESTs were used as "props' at the school or as 'status symbols." Non-NESTs were seen as having superior explicit knowledge of English grammar, even though their language competence was questioned. Non-NESTs were also viewed as being stricter teachers.

Interestingly, the impressions of NESTs and non-NESTs were not necessarily borne out by classroom observation. Although the non-NESTs reported having problems with "basically every aspect of competence," all of them were fluent in English and all but one used English almost exclusively during their lessons. Their lessons tended to focus on some aspect of grammar, but they included communicative tasks to teach the grammar in context. They also did more error correction, checked student work more consistently, and assigned more homework. Although their lessons were "far from being perfect," the NESTs had prepared thoroughly for their lessons, which had clear structures with activities linked to each other in a logical order. The NESTs did not correct every student error and their classes had a relaxed atmosphere, but this may have been in part because they taught only conversation.

Arva and Medgyes conclude that the differences observed between the NESTs and non-NESTs cannot be attributed solely to their nativeness/nonnativeness, as there were also differences in their preparation, training, and experience. It is also important to note that the teachers' perceptions were not necessarily reliable. Both NSs and NNSs can be effective in their own ways and on their own terms, and we should be careful not to judge teaching effectiveness based on preconceived notions or stereotypes.

In spite of overwhelming evidence that NNS can make highly competent language teachers, language students may not realize it. Language schools, 
especially those in the private sector, may face a dilemma if they want to attract students. If potential students ask for native English speakers, schools may feel pressured to hire NESTs, even those who are less qualified, as a practical business decision.

In 1991, the international TESOL organization issued a "Statement on Non-Native Speakers of English and Hiring Practices," which was followed by a 1996 "Position statement against discrimination of nonnative speakers of English in the field of TESOL." Here are some excerpts from the 1996 statement:

For decades there has been a long-standing fallacy in the field of English language teaching that native English speakers are the preferred teachers because they are perceived to speak "unaccented" English, understand and use idiomatic expressions fluently, and completely navigate the culture of at least one English-dominant society, and thus they will make better English as a second language (ESL) or English as a foreign language (EFL) teachers than nonnative English speakers. As a result, nonnative Englishspeaking educators have found themselves often implicitly, and sometimes explicitly, discriminated against in hiring practices or in receiving working assignments in the field of teaching ESL or EFL.

However, as English language learners, nonnative English-speaking educators bring a uniquely valuable perspective to the ESL/EFL classroom, and so can closely identify with the cross-cultural and language learning experience that their students are experiencing ....

The distinction between native and nonnative speakers of English presents an oversimplified, either/or classification system that does not actually describe the range of possibilities in a world where English has become a global language. More important, however, the use of the labels "native speaker" and "nonnative speaker" in hiring criteria is misleading, as this labeling minimizes the formal education, linguistic expertise, teaching experience, and professional preparation of teachers ....

TESOL strongly opposes discrimination against nonnative English speakers in the field of English language teaching .... All English language educators should be proficient in English regardless of their native languages, but English language proficiency should be viewed as only one criterion in evaluating a teacher's professionalism. Teaching skills, teaching experience, and professional preparation should be given as much weight as language proficiency.

In spite of TESOL's proclamations, one can still find cases of discrimination in the U.S. The Department of Education of the state of Arizona, which has a large Hispanic population, recently told school districts that they must remove teachers from ESL classrooms if their spoken English is too heavily accented or ungrammatical (Jordan, 2010). The action was condemned by both TESOL (TESOL and AZ-TESOL, 2010) and the National Council of Teachers of English (NCTE, 2010), which wrote: 
This edict is dangerously misguided. Confirmed by research and by policy positions adopted by the National Council of Teachers of English, what matters most in teaching non-native English language learners is not elocution or adherence to a single dialect or speech pattern. What matters most is understanding students and the dynamics of language learning.

This move is troublesome on several levels. First, it targets primarily Hispanic teachers, some of whom were recruited from Latin America in the 1990s as part of a bilingual education program in Arizona. One can't help but wonder if this is just an additional example of anti-immigrant sentiment in the state. Second, it is not clear what criteria will be used to determine whether or not a teacher's English is too ungrammatical or too heavily accented. In fact, everyone has an accent of some sort, and I have heard monolingual English speaking teachers make grammatical errors in their speech. Perhaps most importantly, the policy is misguided when considering the students' best interests. Hispanic teachers who are bilingual in English and Spanish are especially well-suited to teach Arizona's large Hispanic population since they understand their students' culture, can help them integrate into the school system, and can more effectively communicate with students' families. Furthermore, recent research from the University of Haifa, Israel (Leikin, et al, 2009) found that English language learners could better understand teachers whose accents matched their own. This suggests that Hispanic children might actually learn better from teachers with Spanish-accented English.

Cook (1999) makes the point that non-native speakers are routinely compared to native speakers, and in a sense viewed as deficient native speakers. Their language skills are criticized or corrected in the instances where they fall short of the native speaker model. In fact, a common measure of the success of NNSs is the amount of foreign accent they have and whether or not they can 'pass' as native speakers in their oral skills. However, Cook maintains that NNSs should be treated as speakers in their own right, and not compared to the unrealistic and indefinable native speaker norm. Regardless of their language abilities, NNSs are not NSs and they never will be; more importantly, why should they be?

Other cases of discrimination in the job market are not hard to find. A recent perusal of job advertisements on Dave's ESL Café (Sperling, n.d.) showed that bias in favor of NESTs is still widespread. Well over half of the advertisements that I viewed listed "native speaker of English" among the job requirements. Some also indicated that the applicant must hold a passport from the U.S., the UK, Canada, Australia, Ireland, or New Zealand. (For further documentation of discriminatory hiring practices, see also Govardhan, Nayar, \& Sheorey, 1999; Illes, 1991; Lee, 2000; and Takada, 2000.)

My concern over unfair hiring practices goes beyond mere personal indignation. The hiring of unqualified NSs undermines our profession. Unqualified NSs are often young adventurers willing to work part-time, for less money, and without benefits. This does a disservice to those of us, NSs as well as NNSs, who are 
true professionals, who deserve respect for our work, and who deserve to earn a decent living. Furthermore, it is unfair to the underqualified NS him or herself, who, because of a lack of professional credentials, can more easily be exploited by an unscrupulous employer. I do not mean to imply that people who run language schools are necessarily unscrupulous, but the possibility exists for an unqualified NS to work long hours, in poor conditions, for little pay and no benefits with no recourse or official channel for complaints. Finally, it does a disservice to students who spend their time and money on language classes with the belief that they are receiving high quality, competent instruction, when in fact they may not be. This issue is summed up very well in a 1999 TESOL Quarterly article by Govardhan, Nayar \& Sheorey:

... the exploding demand to learn English in the developing countries [has] led to unscrupulous private enterprise exploiting the gullible. To run and operate a financially successful English language school or English training program in a number of countries (even when they are run by local business people who have little or no knowledge of EFL), the only qualification often expected and required is that the front-line personnel be natives of one of the traditional English-speaking countries . . . . This becomes exploitative in both directions, in that the host nationals often pay to be taught by native speakers with enthusiasm and good intentions but little training or even linguistic expertise in English, while the teachers, being aware of their inadequacy, are in no position to protest against having to work long hours with inadequate remuneration. (Govardhan, Nayar \& Sheorey, 1999: 116.)

\section{Part 2: The State of Foreign Language Teaching in the United States}

Up until now I have focused on the teaching of English as a second or foreign language and the lack of respect given to professionals in the field, especially those who are non-native speakers; and persistent discrimination in hiring practices. Perhaps we should not be surprised by the current state of affairs since English has become the global lingua franca. There is tremendous demand for English around the world, and hiring decisions may be determined by supply and demand. However, I believe that lack of professional respect extends beyond the field of English language teaching to teachers of other languages.

After teaching English as a second and foreign language for many years, I was hired to teach Spanish as a foreign language in the U.S. This enabled me to see the issue of native vs. non-native speaking teachers from the other side; and it also made me aware of attitudes towards language teaching more broadly. Foreign language professors in the U.S. sometimes feel compelled to defend the value of their teaching and scholarship. In a country notorious for its lack of ability in foreign languages, professors outside of the discipline have little understanding of what the study of modern languages entails. I like to compare it to a 
famous quip by cartoonist Bob Thaves referring to the famous 1930s dance team of Fred Astaire and Ginger Rogers: "Ginger Rogers did everything Fred Astaire did, but backwards and in high heels." Our language majors do everything that an English, history, or linguistics major does, only in a foreign language.

Examples can also be found in the popular media. Let me give you an example from "The Savings Experiment," a regular feature on America Online's Money and Finance webpage, which investigates a variety of everyday activities and purchases to identify ways to save money. For example, one segment shows how to save money by making your own soda at home; another considers which makes the cheapest pet, a cat or a dog. In among "experiments" for how to save money on laundry detergent or choosing between frozen, homemade, and takeout pizza, was one that caught my eye: "Learn a language, earn a passport to savings." In this segment, Lou Carlozo compares the cost of traditional in-person classes to online learning sites such as Live Mocha and Babbel.com; to self-study using iTunes and podcasts; and to the popular Rosetta Stone $^{\circledR}$ software. Among his conclusions, Carlozo writes: "Even if you thrive in a class setting, it's hard to justify paying for class instruction that costs around $\$ 20$ an hour when much thriftier options exist." This comparison is troubling for many reasons. First, it trivializes the tremendous time and effort that one must devote to the study of another language, not to mention the professional preparation of language teachers, by comparing the endeavor to something as mundane as choosing a washing powder or a pizza. The fact that a comparison is made among such disparate ways of studying a language implies that such a comparison can reasonably be made. There is a world of difference between studying a language in a classroom with a teacher and listening to a foreign language podcast or completing exercises from a foreign language software package.

Although I consider such a comparison absurd, it is more insidious than that: Some institutions in the U.S. are choosing to replace language teachers with software programs. Self-study language programs can be extremely valuable for those who want to learn a language but do not have access to a traditional classroom or time to devote to the regular structure of a formal class. My objection is not to software programs per se, but to the implication that learning through a software program can be equivalent to, as good as, or even better than classroom learning with a teacher.

In the current economic climate in the U.S., public schools from the primary to the tertiary level have been dealt severe budget cuts and are under continuing pressure to cut costs wherever they can. Not surprisingly, an institution can provide a software program for less than the cost of teachers' salaries. The state of New Jersey, for example, was hit with $\$ 820$ million in cuts to education, and has targeted elementary school foreign language programs as a way to reduce costs (Rundquist, 2010). One school district has already adopted Rosetta Stone ${ }^{\circledR}$ for its elementary school Spanish classes, reportedly saving the schools just under $\$ 200,000$ by eliminating three Spanish teachers. Superintendent of the Ridgewood school district, Daniel Fishbein, estimated that Rosetta Stone ${ }^{\circledR}$ would cost 
the district about $\$ 50,000$. Other districts in the state are expected to follow suit (Rundquist, 2010).

Such a decision might make sense to a school administrator whose job it is to stay within a limited budget. The administrator in Ridgewood, New Jersey may have no knowledge of second language acquisition theory, and perhaps little to no experience in foreign language learning. However, the long term ramifications of such a decision remain to be seen.

The University of North Carolina at Chapel Hill, the oldest public university in the United States, recently announced that all introductory Spanish classes would be taught entirely online, and other romance languages may soon do the same (James, 2010). The change was reportedly made due to budget cuts and limited classroom space. According to an article in the university's Daily Tar Heel newspaper in March of 2010, "Research data show that while students in the online classes were only narrowly outperformed by traditional class students in most categories, their pronunciation scores were drastically lower" (James, 2010). I can't help but wonder how the research data were collected. Was oral proficiency measured? Did the university take into account student preferences? Will students enrolled in the new, entirely online course be motivated to continue studying the language, or will they drop language study as soon as they have completed the minimum requirement?

My outrage at replacing teachers with software packages may seem selfserving. After all, I am a language teacher and I don't want to lose my job. But as an analogy, let's consider a field other than language teaching. What if an institution decided to save money by eliminating its history teachers and, in their place, provided students with programs from the History Channel? After all, the programs on the History Channel are outstanding, accurate and wellresearched. However, it is difficult to imagine an educator or administrator making such a proposal, and even more difficult to imagine it being taken seriously.

Foreign language programs across the U.S. are experiencing reductions in their faculty, and some programs are being eliminated entirely, even at the tertiary level. Drake University in Iowa eliminated its foreign language department in 2001, a precursor to what was to come. Earlier this year, Louisiana State University announced that it would completely eliminate programs in Swahili, Russian, Japanese, and Portuguese, which enrolled 161, 113, 105, and 36 students, respectively. The decision was made in spite of the fact that the College of Arts and Sciences requires 4 semesters of foreign language study (Threlkeld, 2010). The University of Nevada-Reno has also proposed eliminating majors in German, French, and Italian, which would leave Spanish as the only foreign language major at the school (Verderosa, 2010).

In a highly publicized decision, the State University of New York (SUNY) at Albany will close its departments of French, Russian, and Italian, again due to severe budget cuts. Once current students graduate, Spanish will be the only remaining language department at the large state university (Jaschik, 2010; Lee, 2010). Language departments have trouble justifying the value of their programs to administrators concerned with cost effectiveness. A professor of history, 
economics, or political science, for instance, can lecture to hundreds of students in a single class, something that cannot be done in a foreign language classroom. As SUNY Albany French professor Eloise Briére pointed out, "You cannot teach languages to an auditorium of 200. It is the nature of what we do that we are then seen as unproductive" (Jaschik, 2010). Ironically, the motto of SUNY-Albany, displayed prominently on the school web page, is "The World Within Reach."

What is most puzzling about the decline in foreign language study in the U.S. is that we are in a period of unprecedented globalization for which knowledge of foreign languages and cultures is more valuable than ever before. Support for foreign language study should be exploding rather than imploding. Insight into this paradox came to me recently from a comment made by a humanities professor who argued that globalization did not justify foreign language study because North Americans can travel nearly anywhere in the world and communicate in English. To a certain extent, he is right that we can, but this does not mean that we should. In spite of its global lingua franca status, English is not spoken by everyone around the world. Furthermore, North Americans who expect to use English wherever they travel will miss out on subtle yet important details in their cross-cultural communication; they are limited to a superficial understanding of the people with whom they are communicating; and they show a marked lack of respect for other cultures. Lack of competence in foreign languages has put North Americans at a real disadvantage both economically and politically.

The federal government recognizes the need for foreign language competence and has identified a list of 'critical languages' that are especially needed in the military and in the diplomatic corps. The U.S. Department of State Bureau of Educational and Cultural Affairs offers a Critical Language Scholarship Program to teach thirteen 'critical need' foreign languages. The purpose of the scholarship program is "to expand dramatically the number of Americans studying and mastering critical need foreign languages." Languages listed are: Arabic, Persian, Azerbaijani, Bengali, Hindi, Indonesian, Korean, Punjabi, Turkish, Urdu, Chinese, Japanese, and Russian. You may remember that two of these languages, Japanese and Russian, are among those cut by Louisiana State University and by SUNY-Albany.

According to two Government Accountability Office (GAO) reports from 2009, some U.S. agencies are ill-equipped in foreign-language translation. Since the September 11, 2001 terrorist attacks, the FBI and other government agencies have had "sizable translation backlogs, which means many pieces of foreignlanguage intelligence have gone unreviewed" (Kollipara, 2010). Furthermore, $31 \%$ of U.S. State Department officials in "language-heavy posts" were not qualified for their positions in 2009, up two points from 29\% in 2005 (Kollipara, 2010).

In spite of the gloomy picture presented above, there is hope for the field of foreign language education. In July of 2010, a bill was introduced to Congress that would encourage second language proficiency for all Americans. The Excellence and Innovation in Language Learning Act, H.R. 6036, would direct the Secretary of Education to undertake a variety of activities to promote elementary and secondary foreign language learning at the national level. At the time 
of this writing, the bill had been referred to the Subcommittee on Higher Education, Lifelong Learning, and Competitiveness, and was in the first step of the legislative process.

Knowledge of a foreign language is undoubtedly essential for foreign policy and for the global economy. However, in emphasizing the instrumental value of foreign language proficiency, it is important that language educators not lose sight of the broader reasons for studying a foreign language, perhaps the reasons that draw teachers into the profession in the first place. Russell Berman, professor at Stanford University and vice president of the Modern Language Association, reminds us of the importance of foreign language study in one's education:

Second language acquisition is a key component of education because it builds student ability in language as such. Students who do well in a second language do better in their first language. With the core language skills - abilities to speak and to listen, to read and to write - come higher-order capacities: to interpret and understand, to recognize cultural difference, and, yes, to appreciate traditions, including one's own. Language learning is not just an instrumental skill, any more than one's writing ability is merely about learning to type on a keyboard. On the contrary, through language we become better thinkers, and that's what education is about ... (Berman, 2010)

Language educators help students develop useful skills that may help them advance their careers. Through foreign language study, learners broaden their minds and expand their mental capacities even if they never use their foreign language skills in a professional setting. Whether you teach English, Spanish, Chinese, or Arabic; whether you teach your native language or one that you learned in school; teaching languages is valuable.

\section{Notes}

1 There is a substantial amount of professional literature on non-native English-speaking teachers, including Braine (1999) and Llurda (2005).

2 The issue of appropriate models and targets in English language instruction is also discussed in Bruton, 2000.

\section{Bibliography}

Arva, V. \& P. Medgyes (2000). Native and non-native teachers in the classroom. System, 28, 355-372.

Berman, R. (2010, November 23). Foreign language for foreign policy? Inside Higher Ed. Retrieved from http://www.insidehighered.com/views/2010/11/23/ berman 
Braine, G. (Ed.). (1999). Non-native educators in English language teaching. Mahwah, NJ: Lawrence Erlbaum.

Bruton, A. (2000). Distinctions \& Dichotomies. English Teaching Professional, 15, 17-18.

Carlozo, L. (2010, June 1). Savings experiment: Learn a language, earn a passport to savings. The Savings Experiment. Retrieved from http://www.walletpop.com/blog/2010/06/01/savings-experiment-learn-a-language-earn-apassport-to-savings/\#ixzz15fK0mMnV

Cook, V. (1999). Going Beyond the Native Speaker in Language Teaching. TESOL Quarterly, 33, 185-209.

Council of American Overseas Research Centers (n.d.). Critical language scholarship program. Retrieved November 24, 2010, from http://www.clscholarship.org/

Govardhan, A., B. Nayar \& R. Sheorey (1999). Do U.S. MATESOL Programs Prepare Students to Teach Abroad? TESOL Quarterly, 33, 114-125.

Graddol, D. (1997). The future of English? A guide to forecasting the popularity of the English language in the 21 $1^{\text {st }}$ century. London: British Council.

H.R. 6036--111th Congress: Excellence and Innovation in Language Learning Act. (2010). In GovTrack.us (database of federal legislation). Retrieved November 23, 2010, from http://www.govtrack.us/congress/bill.xpd?bill=h111$6036 \&$ tab $=$ summary

Illés, É. (1991). Correspondence. ELT Journal, 45, 87.

James, E.A. (2010, November 22). Spanish classes to move online. The Daily Tar Heel. Retrieved from http://www.dailytarheel.com/

Jaschik, S. (2010, October 4). Disappearing languages at Albany. Inside Higher $E d$. Retrieved from http://www.insidehighered.com/

Jordan, M. (2010, April 30). Arizona grades teachers on fluency: State pushed school districts to reassign instructors with heavy accents or other shortcomings in their English. The Wall Street Journal. Retrieved from http://online.wsj.com/

Kollipara, P. (2010, June 12). Government still trying to catch up on foreign language. capabilities. The Hill. Retrieved from: http://thehill.com/homenews/ senate/102833-government-still-trying-to-catch-up-on-foreign-language-capabilities

Lee, I. (2000). Can a Nonnative English Speaker Be a Good English Teacher? TESOL Matters, 10, 19.

Lee, S. (2010, November 15). UAlbany language cuts spark petition. Times Union. Retrieved from http://www.timesunion.com/

Leikin, M., Ibrahim, R., Eviatar, Z. \& Sapir, S. (2009). Listening with an accent: Speech perception in a second language by late bilinguals. Journal of psycholinguistic research, 38, 447-57.

Liu, J. (1999). Nonnative-English Speaking Professionals in TESOL. TESOL Quarterly, 33, 85-102.

Llurda, E. (Ed.). (2005). Non-Native Language Teachers: Perceptions, Challenges and Contributions to the Profession. Netherlands: Springer. 
Medgyes, P. (1994). The non-native teacher. London: Macmillan Publishers.

National Council of Teachers of English (2010, June 7). NCTE speaks out on Arizona Department of Education ruling on teacher speech. Retrieved from http://www.ncte.org/library/NCTEFiles/Involved/Action/NCTEpositiononAZELLrules.pdf

Nunan, D. (2003). The impact of English as a global language on educational policies and practices in the Asia-Pacific region. TESOL Quarterly, 37, 589-613.

Rosetta Stone (n.d.). Rosetta Stone. Retrieved November 24, 2010, from http:// www.rosettastone.com/

Rundquist, J. (2010, June 27). Computer programs replace foreign language teachers in N.J. classrooms after budget cuts. The Star-Ledger. Retrieved from http://www.nj.com/

Sperling, D. (n.d.). Dave's ESL café international job board. Retrieved November 21, 2010, from http://www.eslcafe.com/joblist/

Takada, T. (2000). The Social Status of L1 Japanese EFL Teachers. TESOL Matters, $10,23$.

TESOL (2010, May). TESOL and AZ-TESOL joint statement on the teacher English fluency initiative in Arizona. Retrieved from http://www.tesol.org/s_tesol/seccss.asp?CID=32\&DID=37

TESOL (2006, March). TESOL position statement against discrimination of nonnative speakers of English in the field of TESOL. Retrieved from http://www. tesol.org/s_tesol/seccss.asp?CID=32\&DID=37

TESOL (1991, October). TESOL statement on non-native speakers of English and hiring practices. Retrieved from http://nnest.asu.edu/articles/TESOL_ Statement\%5B1\%5D.pdf

Threlkeld, C. (2010, September 1). University to eliminate 4 foreign languages. The Daily Reveille. Retrieved from http://www.lsureveille.com/

Verderosa, T. (2010, April 6). Language departments face elimination. The Nevada Sagebrush. Retrieved from http://nevadasagebrush.com/

Willis, J. (1996). A Framework for Task-Based Learning. Harlow, England: Longman. 
